\title{
ACTIVIDADES DEL CENTRO DE ESTUDIOS IBERO-AMERICANOS DE LA UNIVERSIDAD CAROLINA, 2018
}

En el año correspondiente, el Centro de Estudios Ibero-Americanos de la Universidad Carolina de Praga (sede: Hybernská 3, Praha 1; dirección postal: nám. Jana Palacha 2, 11638 Praha 1, República Checa; dirección electrónica: ibero@ff.cuni.cz), un lugar de trabajo interdisciplinario dedicado a la investigación y la docencia en el área mencionada, continuó desempeñándose como departamento independiente en el marco de la Facultad de Filosofía y Letras, con la finalidad de ofrecer cursos de

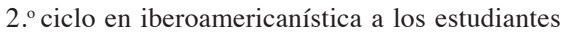
que ya hayan alcanzado el grado de licenciatura (Bc.) en sus carreras -particularmente de Filología Románica-Español, Filología Inglesa-Americanística, Traducción e Interpretación-Español, Historia, Etnología, etc.- y quisieran recibir el grado de máster (Mgr.) en estudios iberoamericanos. Otros estudiantes pueden cursar las asignaturas como optativas. El Centro ofrece también estudios de doctorado en doctorado en estudios iberoamericanos.

De la dirección del Centro de Estudios Ibero-Americanos desde su independización de otras entidades de la Facultad como departamento y como carrera de $2{ }^{\circ}$ ciclo (máster) en los años noventa del siglo pasado, estaba encargado ininterrumpidamente, hasta finales de noviembre de 2018, el Prof. PhDr. Josef Opatrný, CSc. Su gran merecimiento ha sido el enlazamiento fructífero con la tradición anterior iberoamericanista (de investigación y docencia): primero la constitución de los estudios iberoamericanos a nivel de pregrado en forma de especialización (para estudiantes de otros departamentos de la Facultad de Filosofía: Historia, Estudios Románicos, Etnología, etc.) y, después, como una disciplina totalmente autónoma a nivel de máster. Tras su estabilización a lo largo de años siguió el establecimiento de los estudios doctorales. Así mismo, durante toda su carrera docente y de investigación, el Prof. Opatrný se ha merecido un renombre internacional y, gracias a él y a su precursor Josef Polišenský, los estudios iberoamericanos de Praga ocupan un lugar reconocido entre los centros especializados en esa carrera ya desde su formación en los años 60 del siglo XX.

A partir del 1 de diciembre de 2018, con base en un concurso de oposiciones institucionales, encabeza el Centro como directora por el período de tres años PhDr. Simona Binková, CSc. Sin embargo, el Prof. Opatrný sigue en sus actividades tanto docentes, como de investigación (véase más abajo).

Además de su cargo de Vice-Decana de Relaciones Internacionales de la Facultad de Filosofía, sigue formando parte del cuerpo docente del Centro también la Prof. Markéta Křížová, Ph.D., nombrada por decreto del Presidente de la República como catedrática, a finales de 2018.

Los afiliados más jóvenes que forman parte del colectivo docente desde 2016 y 2017, respectivamente, son PhDr. Radek Buben, Ph.D. que asumió los deberes de M. Křížová volviéndose secretario científico del Centro, coordinador del Centro para pasantías en el extranjero y los programas de cooperación internacionales como ERASMUS, CEEPUS, etc., y Mgr. Monika Brenišínová, Ph.D. que se volvió la redactora ejecutiva de la revista Ibero-Americana Pragensia. Desde 2016, el anuario cambió de estatuto convirtiéndose en revista con una periodicidad de dos números al año y con el sistema de revisión por pares. La tarea de revisar las traducciones al español la desempeña la Mgr. Lillyam Rosalba González Espinosa, Ph.D., egresada del Centro.

En la impartición de los cursos siguieron participando las profesoras de la Facultad de Filosofía Prof. PhDr. Anna Housková, CSc. (Literatura hispanoamericana), PhDr. Anna Mištinová, Ph.D. (El Español de América) y recientemente Mgr. Dora Poláková, Ph.D. (Seminario de literaturas hispanoamericanas), las tres del Instituto de Estudios Románicos, y como colaboradores externos Prof. RNDr. Bohumír Janský, CSc., Doc. RNDr. Eva Janská, Ph.D. y RNDr. Jiří Vágner, Ph.D., los tres 
de la Facultad de Ciencias Naturales de la Universidad Carolina, en materias tocantes a geografía, demografía y migraciones.

En cuanto a la participación en asuntos académicos a nivel de la Facultad, Josef Opatrný sigue formando parte del Consejo Científico de la Facultad de Filosofía y del Consejo de Gerentes del programa de estudios en Historia.

Desde enero de 2018, se incorporaron al colectivo del Centro a nivel de investigadores de medio tiempo PhDr. Lukáš Perutka, Ph.D. y Mgr. Kateřina Gabrhelíková, doctoranda del Centro, los dos en los marcos del programa de investigación de la Facultad de Filosofía denominado KREAS (ver más abajo, Tareas de investigación). Ésta, para el período programado hasta principios de octubre de 2020, y aquél como post-doc egresado del Centro, hasta el final del proyecto en 2022.

El Centro sigue contando con los acervos de su propia biblioteca iniciada en los años de su fundación (años sesenta del siglo pasado) que forma parte de los fondos de la llamada Biblioteca del Palacio Špork (y, en el marco más general, de la Biblioteca de la Facultad de Filosofía de la Universidad Carolina). Los bibliotecarios, Tomáš Mlynář y Pamela Kraftová, son encargados del servicio de préstamo y de inventarización y catalogación de las adquisiciones.

En la dirección del club estudiantil IBEROklub siguió Eleni Dimelisová, doctoranda de iberoamericanística.

\section{Las tareas básicas del Centro: enseñanza}

Se siguió la labor docente, llevada a cabo en dos áreas:

$1^{\circ}$ - Desarrollando el curso de iberoamericanística a nivel de máster, compuesto por las siguientes asignaturas: Culturas nativas hasta 1492 y Conquista (M. Křížová / M. Brenišínová), Historia Colonial de América Latina (S. Binková), Historia del siglo XIX (J. Opatrný) e Historia del siglo XX (J. Opatrný / L. Perutka), Fuentes para el estudio de la Historia de Iberoamérica (S. Binková), Historiografía de América Latina (M. Křížová), Geografía (M. Janský y E. Janská), Literaturas Hispanoamericanas (A. Housková y D. Poláková), El Español de América (A. Mištinová). Para los estudiantes no hispanistas se proporcionan cursos de Introducción al estudio de Historia y Cultura de América Latina (J. Opatrný) y de Español para principiantes (S. Binková). Todo este curso está concebido como curso de $2{ }^{\circ}$ ciclo y de especialización en Historia de América Latina - Iberoamericanística; sin embargo, sus clases también están abiertas -como optativas- a estudiantes de otras carreras de la Facultad de Filosofía. Además, se prepararon diferentes cursos nuevos. En 2018, R. Buben impartió en el Centro el curso sobre América Latina contemporánea, los Sistemas políticos de América Latina e Historiografía II. En la docencia (materias optativas) participaron igualmente la profesora Dra. Luz Araceli González Uresti del TEC Monterrey (Historia y Cultura de México) que pasó en Praga su semestre sabático y la estudiante de estudios doctorales Eleni Dimelisová (La cultura maya).

$2^{\circ}$ - Dando clases de Historia y Cultura Españolas e Hispanoamericanas en el Instituto de Estudios Románicos y en el de Traductología - Español (J. Opatrný), y de Historia de Portugal y Brasil en el Instituto de Estudios Románicos (S. Binková). Además, se proporciona también el curso de Historia de los Estados Unidos para los estudiantes del Instituto de Traductología - Inglés ( $\mathrm{J}$. Opatrný). Los profesores recientemente integrados participan también en los cursos del Instituto de Historia (p. ej. Temas de la Historia de América Latina - M. Křížová, L. Perutka, R. Buben, M. Brenišínová). Esas clases forman parte del programa de grado de los respectivos Institutos.

Además, se impartieron clases para los estudiantes del programa Erasmus en el Instituto de Historia Universal (M. Kř́̌žová). Los profesores del Centro participaron también como miembros de comisiones de estudios de grado y doctorales en la Facultad de Filosofía y en la Facultad de Ciencias Sociales de la UC y en la Escuela Superior de Economía (VŠE).

En el Centro, en 2018, fueron defendidas en total 9 tesis de $2^{\circ}$ ciclo de estudios (máster). Además, el profesorado participó en orientar, o en oponer las tesis -tanto del $1^{\text {ero }}$, como $2^{\circ}$ ciclo- en otros departamentos e institutos de la Universidad Carolina, eventualmente de otras universidades del país.

En el Centro se imparte también un curso de posgrado con especialización en estudios iberoamericanos. En 2018 fueron defendidas dos tesis doctorales: la de Mgr. Iva Deylová (Kulturní vztahy mezi bývalým Československem a vybranými státy andského regionu v letech 1945-1989 [Relaciones Culturales entre la ex-Checoslovaquia y los países selectos de la región andina en los años 1945-1989], bajo la tutoría de Simona Binková) y la de doc. JUDr. Peter Vyšný, 
Ph.D. (Štát, právo a každodenný život v aztéckom Tenochtitlane [Estado, derecho y la vida diaria en el Tenochtitlan azteca], dirigida por Markéta Křížová).

\section{Seminario Iberoamericanista}

El Seminario Iberoamericanista del Centro de Estudios Ibero-Americanos se efectúa cada martes del semestre corriente, a las 16 horas, invariablemente desde los años 60 del siglo XX cuando fue establecido. Surgió como plataforma de reunión de académicos, estudiantes y egresados, personas cercanas a la problemática del mundo hispano-luso-americano, para convertirse en los años 90 en un seminario regular acreditado en la nueva disciplina de iberoamericanística estudiada a nivel de máster, materia obligatoria para los estudiantes que presentan y discuten aquí sus tesis. Sin embargo, este seminario conserva también su carácter y razón original: ser un lugar de presentación de los estudiantes y docentes locales, al igual como de acogida de profesores visitantes y espacio abierto para el intercambio de opiniones. Por lo general, cada semestre se efectúa un promedio de 12 a 14 seminarios. Por eso, es imposible marcar a todos los participantes, estudiantes y profesores internos, expondremos entonces sobre todo a los conferenciantes extranjeros y colaboradores checos externos.

En 2018, en el semestre de invierno, la doctoranda del Centro Laura Martínez Abarca (México) ofreció un curso basado en películas que tratan el tema latinoamericano desde la conquista hasta los problemas actuales. El Ministro-Consejero de la Embajada del Perú en la República Checa Óscar Paredes Loza presentó a los estudiantes la XXIII Edición del Premio Iberoamericano organizado anualmente por las Embajadas de América Latina, España y Portugal en la República Checa para los estudiantes de las Universidades checas ya desde 1994 y los incentivó para participar con sus trabajos. Los colegas Sigfrido Vázquez y David Esparza, ambos de España, pero los dos colaboradores desde hace varios años en las universidades checas, presentaron su discurso sobre Historia versus política. Martin Nekola, politólogo e historiador, autor de decenas de libros, habló sobre la emigración checoslovaca a los EE. UU. y América Latina después de 1918. El historiador Jaroslav Bouček, esta vez como editor de las memorias de Otakar Hromádko (editorial Epocha, 2017), expuso sobre su pasado de interbrigadista en la Guerra Civil Española. Angélica Morales Sarabia del Centro de
Investigaciones Interdisciplinarias en Ciencias y Humanidades de la UNAM presentó el tema de la materia médica americana basado en textos novohispanos de los siglos XVI a XVII.

En el semestre de invierno, Cecilia Calderón Puente, de la Universidad Autónoma de Chihuahua (México), Facultad de Ciencias Agrotecnológicas, dedicó su charla a los itinerarios culturales en el Camino Real de Tierra Adentro. Manuel Anselmi, de la LUISS (Libera Università Internazionale degli Studi Sociali, Roma), analizó el populismo de Hugo Chávez y de su sucesor, Nicolás Maduro. Por su parte, Luz Araceli González Uresti, del Departamento de Ciencia Política y Relaciones Internacionales del TEC de Monterrey (México), dedicó en dos ocasiones su exposición sobre los asuntos actuales referentes a México: primero, acerca del convenio sobre el libre comercio entre los Estados Unidos, México y Canadá (con el título "México en el Escenario Regional TLCAN - EUMCA") y sus antecedentes, y segundo, sobre Andrés Manuel López Obrador (AMLO) (“¿Hacia un nuevo proyecto de país? Elecciones 2018 en México y perspectivas a partir del triunfo de AMLO"), comentando las expectativas y escenarios posibles para su administración. Yolanda Fabiola Orquera, de la Universidad Nacional de Tucumán, habló sobre Atahualpa Yupanqui (nombre artístico de Héctor Roberto Chavero), cantautor, guitarrista, poeta y escritor argentino, cuya inspiración musical radicó en el folklore argentino. Aldo Marchesi, de la Universidad de la República (UDELAR, Uruguay) presentó una charla sobre la izquierda latinoamericana en los años 60 globales. Al final del año, participó Carla Granados Moya, doctoranda de la Universidad Sorbonne Nouvelle - Paris 3, con un seminario sobre los temas de memorias de disidentes (Sendero luminoso, narcotráfico).

\section{Cursos de verano}

Entre los días 5 y 8 de junio M. Kř́ížová tomó parte en la organización de la escuela de verano Global Europe. Connecting European History, 17th to 21 st Century, destinada a los estudiantes de posgrado del consorcio GRANES (Graduate Interdisciplinary Network for European Studies). M. Křížová además dio una conferencia sobre el tema de las misiones jesuitas y la difusión de información sobre América en el espacio europeo y mundial en la edad moderna.

En los días del 11 de junio hasta el 6 de julio de 2018, el Centro ofreció a los estudiantes del 
Instituto Tecnológico y de Estudios Superiores de Monterrey en México un curso de verano anual (que en ese año sumó la XIX edición en la Universidad Carolina), concebido originalmente como bloque optativo realizado en el extranjero, llamado Valores del mundo cambiante, y que a partir de 2015 ha actualizado su concepción bajo el título Ciudadanía y Europa del Este. Los estudiantes inscritos debieron aprobar las diferentes materias con trabajos escritos y exámenes orales. El curso corre ininterrumpidamente, caso único entre los centros de enseñanza europeos, desde el año 2000, siendo resultado de los convenios interuniversitarios entre ITESM y la Universidad Carolina. Al inicio de la realización del curso en Praga han estado el Dr. Zidane Zeraoui (el cual también figuró varias veces como profesor acompañante) y el Prof. PhDr. Josef Opatrný (gerente del curso hasta hoy día). En los primeros años el curso llegó a tener dos y hasta tres turnos paralelos o consecutivos debido al interés que despertaba Europa Central y Oriental en el México de principios del año 2000 (Praga sirve de buen punto de salida para visitar los países vecinos, como Alemania, Polonia, Hungría o Austria, lo mismo que brinda oportunidades para viajar a los países de Europa del Oeste y del Sur: Inglaterra, Francia, Bélgica, los Países Bajos, o Italia y España). Actualmente, se realiza un curso anual. Entre los varios profesores acompañantes destaca la Dra. Luz Araceli González del Instituto de Relaciones Exteriores del campus Monterrey, conocedora de Praga y de la República Checa y, por lo tanto un gran apoyo de los estudiantes mexicanos y los profesores praguenses. También el fundador del curso por parte mexicana, Dr. Zidane Zeraoui, pocas veces pierde la ocasión de estar presente en la solemne entrega de los certificados a los estudiantes del curso corriente. El transcurso de las actividades docentes igualmente viene acompañado por el apoyo de la Embajada de México en la República Checa (apertura o conclusión solemnes del curso y/o recibimiento de los estudiantes en la misma sede de la Embajada en Praga).

\section{Actividades de investigación, simposios en Praga y publicaciones del Centro}

Durante 2018, los profesores y estudiantes de posgrado tomaron parte en varios proyectos de investigación, tanto en curso anteriormente, como nuevos. El Prof. Opatrný, en los años 2016-2018 participó como miembro de un grupo internacional en un proyecto extranjero: El espacio antillano: génesis, circulación y redistribución de individuos, mercancías, ideas, saberes y modelos (siglos XVIII-XXI), MINECO HAR2015-66152-R, realizado bajo los auspicios del Consejo Superior de Investigaciones Científicas (CSIC), organización pendiente del Ministerio de Ciencia e Innovación español. El objetivo de ese proyecto internacional fue identificar importantes tendencias y momentos claves de la historia caribeña no solamente desde el punto de vista de la interpretación histórica, sino también buscando soluciones efectivas de problemas sociales, económicos y políticos actuales. (Véase: https://www.csic.es/es/proyectos/el-espacio-antillano-genesis-circulacion-y-redistribucion-de-individuos-mercancias-ideas).

La Prof. Kř́ižová, a partir del año 2016, coparticipa en el proyecto GA ČR (19-03474S) Evolucionismus, nacionalismus a rasismus v české a slovenské vědě [Evolucionismo, nacionalismo y racismo en la ciencia checa y eslovaca].

En 2017 se inició el programa intitulado PROGRES previsto hasta el año 2021. Se trata de un apoyo institucional de la ciencia en la Universidad Carolina a largo plazo por parte del presupuesto estatal. El Centro participa en la subdivisión Q9: Historia, la llave para el entendimiento del mundo globalizado. En el año 2018 integraron el colectivo (por parte del Centro de Estudios Ibero-Americanos) Josef Opatrný, Markéta Křížová y Radek Buben.

La Facultad de Filosofía de la Universidad Carolina ha ganado un nuevo proyecto KREAS, a realizarse entre 2018 y 2022, financiado por el Fondo Europeo de Desarrollo Regional - Proyecto "Creatividad y adaptabilidad como condiciones del éxito de Europa en un mundo interrelacionado" (reg. núm.: CZ.02.1.01/0.0/0.0/16_019/0000734). El Centro de Estudios Ibero-Americanos está representado por Josef Opatrný, Markéta Křížová, Radek Buben, Monika Brenišínová y Lukáš Perutka. A partir de octubre de 2018 se incorporó también la doctoranda Kateřina Gabrhelíková.

Praga también fue lugar de numerosos simposios y coloquios, la mayor parte de ellos con participación internacional. Cronológicamente:

En colaboración con la Universidad Autónoma de Madrid se celebró el día 16 de febrero en Praga la conferencia Género, política y religión en España e Iberoamérica: una perspectiva a largo plazo. M. Křížová participó como organizadora y moderadora de la conferencia que tuvo lugar en 
el Centro de Estudios Ibero-Americanos y que fue coorganizada por M. Brenišínová y Darina Martykánová (Universidad Autónoma de Madrid). M. Brenišínová presentó también su ponencia "Arte de evangelización desde la perspectiva de género" y M. Kř́̌žová "Masculinidad jesuita entre el ideal y los dilemas cotidianos de la misión fronteriza americana" (véase las páginas del evento: https:// generoypolitica.ff.cuni.cz).

Uno de los más amplios fue el evento bajo la denominación la Semana Iberoamericana dedicado a celebrar los cien años de las relaciones diplomáticas entre los países latinoamericanos e ibéricos con la República Checoslovaca / Checa, organizado por el Ministerio de Relaciones Exteriores en cooperación con múltiples instituciones del campo de diplomacia, política, comercio, cultura y enseñanza, que se extendió del 19 al 27 de abril de 2018. En su marco, el día 26 de abril de 2018 se celebró en el Centro de Estudios Ibero-Americanos una conferencia del Secretario General de la Organización de los Estados Americanos (en adelante sólo OEA) Luis Almagro quien habló sobre la situación económica y política en varios países latinoamericanos a partir de los años 80 del siglo pasado, y al día siguiente, el 27 de abril, se celebró en el Centro uno de los eventos parciales de la Semana Iberoamericana, un coloquio sobre las tradiciones de los contactos diplomáticos, económicos y culturales en los últimos cien años organizado por J. Opatrný y con amplia participación de colegas ligados al Centro y a los diferentes departamentos de la Facultad (para más detalles, ver aquí las pp. 101-102).

En septiembre, los días 6 y 7, J. Opatrný coordinó en el Centro un simposio internacional denominado Checoslovaquia, Europa Central y América Latina. El periodo de entreguerras. Participaron José Manuel Serrano (Colombia), Luz Araceli González Uresti (México), Mónika Szente Varga y Anita Zalai (Hungría), Paweł Kwiatkowski y Katarzyna Krzywicka (Polonia), Josef Opatrný, Pavel Štěpánek, Jaromír Soukup, Lukáš Perutka, Lukáš Drvota, Maroš Timko, Kateřina Gabrhelíková (todos de la República Checa), y Sigfrido Vázquez Cienfuegos (España). El año que viene se publicará una monografía.

En el mismo mes, M. Kř́̌žová tomó parte en el 8th Triennial International Conference of the Central European Association for Canadian Studies con una ponencia "Moravian Mission in Fairfield (1792-1815): Unhappy ending of the American utopia" que tuvo lugar el 21 de septiembre de 2018 en Praga.

S. Binková participó en septiembre en un simposio internacional intitulado Pensar o passado, compreender o presente, idealizar o futuro, organizado en los días 22 y 23 de septiembre de 2018 en la Universidad Carolina en Praga por la Sociedade Checa de Língua Portuguesa y el Instituto para el estudio de regiones estratégicas, con "Estudantes e professores da Universidade (Carlo-Fernandina) de Praga e o mundo português dos séculos XVII e XVIII".

Markéta Křížová junto con Monika Brenišínová coorganizaron un taller internacional Research in Non-European Areas: Methods, Techniques, Problems, Challenges que se celebró el día 18 de octubre en el Centro de Estudios Ibero-Americanos en Praga. El evento fue preparado en colaboración de dicho Centro, con la Universidad de SS. Cirilio y Metodio en Trnava y en los marcos del proyecto KREAS. La conferencia fue abierta por una charla de Adam Uhnák de la Universidad de SS. Cirilio y Metodio en Trnava "Slovenský etnológ v Mexiku - metódy a techniky etnologického výskumu všpecifickom kultúrnom prostredî" [Un etnólogo eslovaco en México - métodos y procedimientos de la investigación etnológica en un ambiente cultural específico] que tematizó los problemas específicos de la investigación no sólo etnológica en territorios no-europeos, concretamente en México. El taller, en el cual participaron Marek Halbich de Facultad de Humanidades de la Universidad Carolina, estudiantes del Centro (Zuzana Lhotáková y Martin Rataj), así como de la Facultad de Filosofía como tal (Lenka Zahrádková), incluyó también una proyección comentada de un documental etnográfico de Radoslav Hlúšek sobre las procesiones religiosas en México e informes de las últimas excavaciones del Templo Mayor azteca por M. Brenišínová, la cual participó con la ponencia “Od kláštera k člověku: umění na hranici tří vědeckých disciplín” [Del convento al hombre: el arte en el umbral de las tres disciplinas científicas]. Las contribuciones de los participantes trataron problemas metodológicos, teóricos, pero también éticos que acompañan la investigación de campo en las áreas no-europeas. También se prestó atención al tema de la investigación de archivos, encuestas sociológicas, etc. (Para más información véase las páginas del evento: https://vyzkumvmeo. ff.cuni.cz y el texto de L. Bistárová "International Workshop 'Research in Non-European Areas: 
Methods, Techniques, Problems, Challenges'", Ibero-Americana Pragensia 46/2, p. 71.)

Al final del año, el 7 y 8 de diciembre de 2018 se celebró un simposio titulado Latin America and Central Europe in 1968: Political Left, Social Movements and Mutual Influences in the Year of Upheavals con participación internacional (un informe más detallado sobre los participantes y los temas véase: Ibero-Americana Pragensia XLVI/2, p. 72, redactado por Maroš Timko). Por parte del Centro participaron M. Kř́̌žová (la charla "1967: The Founding of Ibero-American Studies in Czechoslovakia at the Background of the Cold War Intellectual Competitions", R. Buben (sobre la izquierda política venezolana) y L. Perutka (sobre la masacre de Tlatelolco y la reacción de los EE. UU.).

En lo que se refiere a las publicaciones colectivas del Centro (y de las instituciones hermandadas):

En 2018 salió a la luz una monografía colectiva preparada en colaboración entre el Depto. de Portugués del Instituto de Estudios Románicos y el Centro de Estudios Ibero-Americanos, y con participación de investigadores de otras instituciones, Brazílie v souvislostech [Brasil en el contexto], eds. Šárka Grausová [i!, recte: Grauová], Alena Rudolfová y Milan Tichý (Editorial Červený Kostelec: Pavel Mervart, 2018, 418 págs., ISBN 978-80-7465-306-3, en checo). En los trabajos de edición intervino también M. Kř̌́žová. La misma como autora, contribuyó al volumen con el tema "Indiáni, nebo Němci? Dilema brazilské společnosti na prahu 20. století a role Alberto Vojtěcha Friče" [Indios o alemanes? El dilema de la sociedad brasileña en el umbral del siglo XX y el papel de Alberto Vojtěch Frič, pp. 319-340]. Por parte de los investigadores del Centro de Estudios Ibero-Americanos aparecen además los estudios de R. Buben, "Ústavní vládnutí bez volební legitimity: Brazílie a problémy viceprezidentského režimu" [El gobierno constitucional sin voto de legitimidad: Brasil y los problemas del régimen de vicepresidencia, pp. 33-64] y de S. Binková, "Brazílie $\mathrm{v}$ české naučné literatuře 19. stoletî́" [Brasil en la literatura enciclopédica y educativa checa del siglo XIX, pp. 301-318]. La doctoranda A. Rudolfová presentó "Zahraniční politika Brazílie v období 1995-2010" [La política exterior de Brasil en el periodo de 1995 a 2010, pp. 65-89]. Participaron también los antiguos doctorandos y/o egresados del Centro: Kateřina Březinová (actualmente
Universidad Metropolitana de Praga), Michal Zourek (Universidad de Buenos Aires - CONICET), Matyáš Pelant (Ministerio de Industria y Comercio de la República Checa), Karel Staněk (Biblioteca Nacional de la República Checa).

Bajo el título Caribe hispano y Europa. Siglos XIX y XX: Dos siglos de relaciones, Josef Opatrný, coord. (=Ibero-Americana Pragensia Supplementum 48, Praga: Editorial Karolinum, 2018, 246 págs., ISBN 978-80-246-3816-4) se publicó una monografía colectiva. Entre muchas otras contribuciones constan la del mismo Josef Opatrný sobre la "Diplomacia checoslovaca y Caribe hispano en los sesenta del siglo XX" (pp. 169-185), de Sigfrido Vázquez Cienfuegos "Cincuenta años de Centro de Estudios Ibero-Americanos" (pp. 1126), así como estudios de otros académicos nacionales (Lukáš Perutka y Lukáš Drvota) y extranjeros (p. ej. José Antonio Piqueras, Imilcy Balboa Navarro, Inés Roldán de Montaud, Manuel de Paz Sánchez, Ángel Dámaso Luis León, Amparo Sánchez Cobos, todos de España; investigadores de las universidades francesas Sylvie Mégevand, Yopane Thiao, Álvar de la Llosa, Etienne Morales, Gabrielle Croguennec-Massol; de Alemania, Michael Zeuske y de Hungría, Katalin Jancsó).

Además, en el año 2018 salió a la luz una monografía de las autoras Monika Brenišínová, Markéta Křížová y Kateřina Březinová, Dějiny umění Latinské Ameriky [Historia del arte latinoamericano, Praha: Editorial Karolinum, 2018, 403 págs., ISBN 978-80-246-3175-2]. El objetivo de esta publicación fue explicar a los estudiantes y al gran público una visión general de la historia del arte de la región, introducirlos en la literatura relacionada con el tema, así como presentarles importantes museos y galerías. Igualmente, se continuó con el objetivo de familiarizarlos con las relaciones entre la República Checa y América Latina en el campo de la cultura y el arte, dirigiéndolos así a su estudio posterior. La publicación contiene también una explicación de términos importantes y está acompañada por un rico suplemento pictórico. Es el primer título de este tipo en el mercado de libros checo.

En lo demás, Josef Opatrný contribuyó con el capitulo "Španělsko, občanská válka a atlantický svět" [España, la Guerra Civil y el mundo atlántico] a la publicación de Zdeněk Maršálek - Emil Voráček et al., Interbrigadisté, Československo a španělská občanská válka. Neznámé kapitoly $z$ historie československé účasti v občanské válce 
ve Španělsku 1936-1939 [Los interbrigadistas, Checoslovaquia y la guerra civil española. Capítulos desconocidos de la historia de la participación checoslovaca en la guerra civil de España 1936-1939, Praha: Historický ústav AV ČR, Ústav pro soudobé dějiny AV ČR, 2017, pp. 10-33, ISBN 978-80-7286-312-9]. J. Opatrný junto con S. Vázquez Cienfuegos escribieron un capítulo intitulado "Cuba y Checoslovaquia durante la Guerra Fría: Estudio de caso", publicado en: José Manuel Azcona Pastor, Israel Escalona Chádez, Mónica García Salgado (eds.), Relaciones bilaterales España-Cuba (siglo XX), Madrid: Sílex Universidad 2018, pp. 366-392, ISBN 978-84-7738.

En el año 2018, aparte de lo ya mencionado, Markéta Křrižová publicó dos estudios más: uno bajo el título "Between «here» and «over there»: Short-term and circular mobility from the Czech Lands to Latin America (1880s-1930s)" , Hungarian Historical Review 7, 2018, pp. 191-218 (ISSN 2063-8647) y el otro intitulado " "The History of Human Stupidity»: Vojtěch Frič and his Program of a Comparative Study of Religions", Ethnologia Actualis 18, 2018, pp. $42-67$ (ISSN 1339-7834).

Simona Binková vio finalmente realizada la publicación de su estudio "Manuel Teles da Silva a jeho vazby $\mathrm{k}$ Portugalsku a k portugalským zámořským územím skrze jeho knihovnu a archiv" [Manuel Teles da Silva y sus relaciones con Portugal y sus territorios ultramarinos vistas a través de su biblioteca y archivo], Zprávy Vlastivědného muzea v Olomouci 316, Olomouc 2018, pp. 5-18 (ISSN 1212-1134).

Aparte de otras actividades ya mencionadas, M. Brenišínová también publicó estudios dedicados a los problemas de la arquitectura y el arte monásticos de la Nueva España del siglo XVI: "Sixteenth-century Mexican Monasteries and Art. An Anthropological Perspective", Ethnologia Actualis 18/1, 2018, (Trnava: Universidad de SS. Cirilio y Metodio en Trnava, pp. 93-124, ISSN 13397834). Además, "Mexické kláštery na pomezí tří vědeckých disciplín: historie, dějin umění a antropologie" [Los conventos novohispanos entre las tres dsiciplinas científicas - historia, historia del arte y antropología], en: Jan Galeta, Martin Šolc (eds.), Architektura mezi myšlenkou a skutečností [La arquitectura entre la idea y la realidad], Brno: Národní památkový ústav, Metodické centrum moderní architektury, 2018, pp. 2-19, ISBN 97880-7480-108-2. Y finalmente "Klášterní umění Nového Španělska 16. století: umění na hranici kultur a vědeckých disciplín" [El arte conventual novohispano del siglo XVI: el arte en la frontera de las culturas y las diciplinas científicas], en: Eva Csémyová, Jakub Hauser, Tereza Johanidesová, Adéla Klinerová (eds.), Přrekračování hranic. Mezioborovost, migrace a mobilita v dějinách umění a př́buzných oborech. Crossing Borders. Interdisciplinarity, migration and mobility in art history and related subjects, Praha: Univerzita Karlova, Filozofická fakulta, 2018, pp. 8-26. La misma fue redactora de los volúmenes 46/1 y 46/2 de Ibero-Americana Pragensia (año XLVI - 2018, Universidad Carolina, Editorial Karolinum 2018, ISSN 0536-2520) que fueron publicados en 2018.

Lukáš Perutka, en coautoría con Milan Balaban y Jan Herman, publicó el estudio "The presence of the Bat'a Shoe Company in Central America and the Caribbean in the Interwar period" (América Latina en la Historia Económica 25/2, mayo-agosto 2018, pp. 42-76). El mismo participó con "La colonia checoslovaca en Argentina y la política exterior de su gobierno en la década de 1920" en el simposio internacional Checoslovaquia, Europa Central y América Latina. El periodo de entreguerras, que se celebró entre los días 6 y 7 de septiembre (ver más arriba).

El día 26 de noviembre se celebró una tertulia llamada La huella praguense de Sergio Pitol organizada por la Universidad Carolina y la Embajada de México en la República Checa. La tertulia literaria tuvo lugar en el Centro de Estudios Ibero-Americanos. J. Opatrný dio su ponencia dedicada a "Sergio Pitol y la iberoamericanística checoslovaca".

El 18 de octubre, se llevó a cabo un taller internacional Research in Non-European Areas: Methods, Techniques, Problems, Challenges donde contribuyó M. Brenišínová que coorganizó el evento, con la conferencia "Od kláštera k člověku: umění na hranici tří vědeckých disciplín" [Del convento al hombre: el arte en el umbral de las tres diciplinas científicas].

El día 23 de noviembre se celebró una conferencia internacional Multiple Modernities in Latin America que tuvo lugar en el Centro Iberoamericano de la Universidad Metropolitana de Praga, en colaboración con KREAS y el Departamento de Estudios Románicos. M. Brenišínová contribuyó con una charla "The history of colonial art in the mirror of modernity: the case of Mexico".

En mayo, L. Perutka tomó parte en dos conferencias domésticas: VII Coloquio Internacional 
de Estudios Latinoamericanos de Olomouc con su ponencia "La inmigración checoslovaca en Sudamérica en la obra de Ferdinand Hýža" (de 3 a 5 de mayo) y Valašsko - historie a kultura II. Obživa en Rožnov pod Radhoštěm, hablando sobre "Kolache a Colatches. Tradice a proměny valašské stravy v Texasu" [Kolache y Colatches. Tradiciones y transformaciones de la dieta valaquia en Texas] (de 23 a 25 de mayo).

Además, dio una ponencia intitulada "Latin America's independence as a missed opportunity for regional cohesion" en la conferencia What makes a region, que tuvo lugar en el suelo de la Facultad de Filosofía y Letras de la Universidad Carolina como un proyecto de KREAS entre los días 27 y 28 de septiembre.

\section{Relaciones a nivel internacional y viajes al extranjero}

Aparte de los numerosos simposios internacionales que se celebraron en Praga y sus actas publicadas (ver más arriba), Josef Opatrný participa en un proyecto internacional apoyado desde 2016 por el Ministerio de Ciencias e Innovación de España concedido al Consejo Superior de Investigaciones Científicas (HAR2015-66152-R).

M. Křížová dio una ponencia "Every Object is the Product of Superstition: Alberto Vojtěch Frič and his Program of the Comparative Study of Religion" en la conferencia Search for Indian America 2 que tuvo lugar entre los días 12 y 13 de febrero en Trnava y fue organizada por la Universidad de SS. Cirilio y Metodio. M. Brenišínová participó con su ponencia "Conventual Architecture in Mexico seen from Anthropological Point of View".

El día 25 de mayo J. Opatrný participó en el congreso internacional organizado por la Latin American Studies Association que tuvo lugar en Barcelona. Dio una charla sobre "Estudios de América Latina en Checoslovaquia durante la Guerra Fría" en el panel Mesa Presidencial: Migraciones, Guerra Fría Solidaridad: Estudios de América Latina desde Europa.

El día 14 de febrero M. Kř́žzová junto con los profesores Milan Kováč (Universidad Comenius de Bratislava) y John Chuchiak (Missouri State University) viajaron a Liberec donde, en el Museo de Bohemia del Norte, se encuentra una falsificación del códice de tipo maya (llamado Códice de Liberec). Se llevó a cabo una investigación básica y documentación del material, su datación preliminar e identificación (principios del siglo $\mathrm{XX}$, uno de los talleres de falsificación en la Ciudad de México). Se está preparando un proyecto para una exploración detallada, datación más precisa y la edición.

La misma dio una conferencia "¿Cuna del hombre americano, o la metrópoli aria? Orientalismo, apropiación y esoterismo en la arqueología y antropología a la vuelta del siglo XX: El caso de Tiahuanaco" en el $56^{\circ}$ Congreso Internacional de Americanistas que tuvo lugar entre los días 15 y 20 de julio en Salamanca.

En agosto, S. Binková tomó parte del coloquio Brasil-República Tcheca: diálogos culturais organizado por el Instituto de Estudos Brasileiros de la Universidade de São Paulo y el Departamento de Portugués del Instituto de Lenguas Románicas de la Universidad Carolina (de esta parte, la organizadora principal fue Mgr. Š́rka Grauová, Ph.D., jefa del Departamento). El evento se llevó a cabo con base en el convenio entre ambas universidades y su motivo fue conmemorar los 90 años de existencia de los cursos de la lengua portuguesa en la Universidad Carolina, del 60 aniversario del establecimiento de la carrera del portugués como disciplina independiente y un poco más de 50 años de la fundación del Centro de Estudios Ibero-Americanos que desde sus inicios proclamaba el interés en el mundo hispanoamericano y el luso-brasileño, conjuntamente. S. Binková dio un panorama de las relaciones checo-brasileñas através de los siglos. Con sus temas participaron varios investigadores tanto checos, como brasileños y Š. Grauová concluyó con una charla sobre los desafíos y las perspectivas de los estudios portugueses en la República Checa. El evento, acompañado de una exposición referente a la historia de los estudios luso-brasileños en la República Checa, contó con los auspicios de la cónsul general de la República Checaen São Paulo Pavla Havrlíková y se celebró el 21 de agosto, coincidiendo con la conmemoración del 50 aniversario de la invasión de los ejércitos del Pacto de Varsovia a Checoslovaquia en 1968.

L. Perutka tomó parte en la conferencia XIX Jornadas Iberoamericanas en Pécs (Hungría) con su charla sobre las reflexiones de la masacre en Tlatelolco y los subsecuentes Juegos Olímpicos de México en la sociedad checoslovaca (entre los días 7 y 11 de mayo).

Al final del año 2018, S. Binková junto con el Prof. RNDr. Bohumír Janský, CSc. de la Facultad 
de Ciencias Naturales de la Universidad Carolina viajaron a Perú con el motivo del homenaje organizado en varios eventos en Lima y en la Amazonía peruana por iniciativa de la Embajada de la República Checa en Perú a nuestro compatriota del siglo XVII / XVIII, el famoso cartógrafo y misionero jesuita Samuel Fritz. El 27 de noviembre, en el Centro Cultural de la Universidad Nacional Mayor de San Marcos en Lima, tuvo lugar un coloquio bajo el título Un jesuita glocal: Samuel Fritz, entre Praga y la Amazonía en el que participaron varios investigadores del Perú y Ecuador, además de los checos. S. Binková presentó al P. Samuel Fritz, SJ en el contexto de su viaje desde Bohemia a las misiones subrayando que él no fue el único, aunque sí el más valiente en conocer pormenorizadamente la naturaleza peruana, conviviendo con sus habitantes en la selva durante varios decenios. B. Janský destacó su importancia para la cartografía del río Amazonas a lo largo de siglos. En un programa vespertino se inauguró en el mismo lugar una exposición relacionada con la vida y obra del homenajeado. En los días siguientes, la delegación encabezada por S.E. el Embajador de la República Checa Ing. Pavel Bechný se trasladó a la ciudad de Yurimaguas, una de las antiguas misiones fundadas por S. Fritz, para celebrar otros eventos allí mismo, inaugurándose un monumento de bronce al fundador, ofreciendo los miembros del grupo otro tipo de charlas para un gran público. Toda la estancia, organizada con mucho esmero por el Embajador, trajo además oportunidades de enlazar contactos con instituciones científicas en Lima.

Aparte de la participación en eventos internacionales en el extranjero (simposios, seminarios, jurados), se efectuaron también varios viajes de investigación.

M. Křížová y R. Buben pasaron dos semanas en Perú (del 22 de septiembre al 4 de octubre). En esa ocasión, M. Křížová investigó fuentes relativas a las primeras expediciones arqueológicas desde Europa Central a la región andina. Además, dio una charla en la Pontificia Universidad Católica del Perú, CISEPA (Centro de Investigaciones Sociológicas, Económicas, Políticas y Antropológicas) sobre "Migraciones temporales, fin del siglo XIX - comienzos del siglo XX: Capítulo subestimado de las relaciones entre Centroeuropa a América Latina" (el 25 de septiembre).

La misma visitó también México, del 4 al 22 de noviembre. El día 8 de noviembre tuvo una ponencia "Identidades múltiples de los misioneros jesuitas en el ultramar, siglos XVII-XVIII" en el Centro de Estudios Interdisciplinarios en Ciencias en Humanidades (UNAM). Pasó el resto de su estancia académica en San Cristóbal de Las Casas, dentro del marco de la "Cátedra Jan de Vos", constituida como homenaje al investigador Jan de Vos en el Colegio de la Frontera Sur y el Centro de Investigaciones y Estudios de Antropología Social (entre los días 9 y 21 de noviembre).

M. Brenišínová visitó la Universidad Autónoma de Madrid (España) en mayo con el objetivo de profundizar y establecer relaciones con expertos locales interesados en la historia del mundo hispanoamericano (Darina Martykánová, Saúl Bermejo). Durante su estancia, se establecieron contactos internacionales como parte de una participación en la prestigiosa conferencia organizada por la Casa de Velázquez (centro de investigación francés en humanidades y ciencias sociales con sede en Madrid) y el MIAS (Madrid Institute for Advanced Study, centro de investigación recién creado). M. Brenišínová, en cooperación con Héctor Ruiz, preparó un seminario "El uso de fuentes visuales en la historia", en el que participaron activamente estudiantes y empleados de la UNAM y la Casa de Velázquez.

En septiembre, M. Brenišínová pasó tres semanas en México. El objetivo fue establecer y desarrollar la cooperación con el Instituto de Investigaciones Históricas de UNAM, el Instituto de Investigaciones Históricas de la Universidad de San Nicolás de Hidalgo, Morelia, el Museo del Templo Mayor y la Escuela Nacional de Antropología e Historia, así como presentar las actividades del Centro y planificar la cooperación futura en el campo de la investigación o publicación. Durante su estancia, visitó también el Archivo General de la Nación y el Archivo Franciscano de la Biblioteca Nacional de Antropología e Historia, donde se dedicó a la investigación sobre las misiones franciscanas y la utopía.

En noviembre investigó en el Archivo General de los Franciscanos de Roma (Italia) donde se enfocó en la actividad misionera de la Orden Franciscana.

L. Perutka, en julio de 2018, visitó los archivos y bibliotecas de Viena (Austria): Österreichische Nationalbibliothek, Universitätsbibliothek Wien, Haus-, Hof- und Staatsarchiv, Kriegsarchiv, Diözesanarchiv Wien. Su propósito era investigar los problemas de la "aventura mexicana" de 
Maximiliano y las actividades misioneras de los sacerdotes checos en los Estados Unidos como parte de la Leopoldinenstiftung.

En septiembre de 2018, L. Perutka visitó Berlín y, en particular, las tres instituciones siguientes: Ibero-Amerikanisches Institut, Bundesarchiv, Das Politische Archiv - Auswärtiges Amt. Los temas estudiados se referían principalmente a la migración, la emigración checa y alemana, y la preservación / transformación de identidades en el extranjero. Los resultados se publicarán en varias formas, ya sean monografías o artículos en revistas o capítulos impactados. Se examinaron fondos y literatura sobre el tema de la competencia económica checa y alemana en México y América Central en el período de entreguerras.

Ibero-Amerikanisches Institut en Berlín fue visitado también por M. Brenišínová, en dos ocasiones: en junio y en octubre. Allí, la misma siguió dedicándose a los estudios e investigaciones antes mencionados sobre la actividad misionera de la Orden Franciscana en América y el tema de las utopías.

En cuanto a los convenios y relaciones interuniversitarias, el más duradero es el curso de verano organizado por el Centro para los estudiantes del ITESM Monterrey, México (véase más arriba). Cada año parten para estudiar en el extranjero también varios estudiantes de máster y de doctorado checos. Este año, además, la Dra. Luz Araceli González Uresti pasó su sabático de agosto a diciembre del 2018 en Praga, ofreciendo durante su estancia un seminario de Historia y cultura mexicana. Su docencia se extendió, de manera virtual, a la segunda semana de enero 2019 con trabajo a distancia con los alumnos y entregas de sus ensayos finales.

En septiembre de 2011 fue inaugurado un programa de estudios a nivel de máster Erasmus Mundus TEMA, "European Territories (Civilisation, nation, region, city): Identity and Development", en cuya realización -aparte de la Universidad Carolina en Praga- participan Eötvös Loránd University (Hungría), École des Hautes Études en Sciences Sociales de Paris (Francia) y Università degli Studi di Catania (Italia). M. Křížová es miembro del consorcio del programa, dirige las tesis e imparte conferencias.

\section{Otro tipo de actividades y divulgación}

En el Centro, ya hace años, se había formado un club de estudiantes, originalmente de doctorado, que solían reunirse informalmente una vez al mes.
Luego, con motivo de excursiones organizadas anualmente a Berlín (Instituto Iberoamericano, Museo Etnográfico de Dahlem) y por Bohemia y Moravia -siempre con temática americanista- se ensanchó el grupo también por estudiantes del $2^{\circ}$ ciclo, realizándose al final un workshop con contribuciones preparadas y una siguiente discusión. De la orientación profesional se encargaban las docentes del Centro, M. Křížová, S. Binková y, posteriormente, M. Brenišínová, mientras que la logística de las excursiones le correspondía a los estudiantes. Este tipo de convivencia con, y entre, estudiantes de distintos niveles continúa de diferentes formas hasta el presente (contacto: https:// www.facebook.com/iberoamerikanistikaffuk/, o iberoklub@seznam.cz).

En 2018, se llevaron a cabo varias actividades dentro del mismo. En febrero se realizó una visita comentada para el grupo estudiantil del Centro de la exposición Indiáni [Indios] que tuvo lugar en el Museo Náprstek en Praga. La exposición fue guiada por M. Brenišínová.

En abril se celebró la presentación y el lanzamiento del libro Dějiny umění Latinské Ameriky, mencionado en los párrafos anteriores. Las autoras M. Křížová, M. Brenišínová y K. Březinová lanzaron su libro en el "Merkádo", el mercado latinoamericano que tuvo lugar en el Kampus Hybernská el 25 de abril, con la participación de Eliška Kaplanová y la redactora Kamila Veselá de la Editorial Karolinum y con la participación del profesor Pavel Štěpánek que bautizó el libro. La presentación fue acompañada por una exposición de las fotos que formaron parte de una convocatoria organizada por el Centro de Estudios Iberoamericanos en el marco del proyecto Dějiny umění Latinské Ameriky. La publicación fue una de las cinco más importantes de la Editorial Karolinum en el año 2018 y fue presentada solemnemente también durante la presentación de los libros de la editorial en los espacios históricos de la Universidad el día 14 de diciembre.

Además, los miembros del Centro participaron en actividades que tenían como objetivo la divulgación y popularización de la ciencia y América Latina en diferentes ámbitos.

J. Opatrný -aparte de los eventos ya mencionados como Iberoamérica - Cien años de amistadque se celebró el día 25 de abril en el Ministerio de Relaciones Exteriores en el marco de la Semana Iberoamericana (para más información sobre el evento ver las pp. 101-102 de este volumen), dio 
también una charla sobre Venezuela en la Cámara de Comercio de la República Checa - Alianza del Pacífico (CESTA) (el 25 de septiembre) y participó en dos actos de presentación de publicaciones en el Instituto Cervantes: primero en el lanzamiento del libro La Mancha roja y La Montaña Blanca, escrito por Anna Mur i Raurell (Praha: Editorial Karolinum, 2018, Ibero-Americana Pragensia Supplementum 45), el 10 de octubre, y segundo en la presentación de los libros de Pavel Marek, Pernštejnské ženy: Marie Manrique de Lara a její dcery ve službách habsburské dynastie ([Las mujeres de la casa de Pernstein. María Manrique de Lara y sus hijas al servicio de la Casa de Austria], Praha: NLN, 2018) y Pavel Štěpánek, Kapitoly z dějin česko-španělských kulturních styků a vztahů ([Capítulos de la historia de las relaciones culturales checo-españolas], Praha: Editorial Karolinum, 2018), el 27 de noviembre. El mismo tomó parte en una discusión sobre la película documental $\mathrm{Co}$ caine Prison (directora Violeta Ayala, 2017) que tuvo lugar el 11 de marzo en el cine Světozor en Praga.

En marzo, M. Brenišínová dio dos conferencias sobre el tema de la muerte: primero "Smrt z antropologické perspektivy a její vnímání v současnosti (ČR a Mexiko)" [La muerte desde la perspectiva antropológica y su percepción en la actualidad (RCh y México)] y segundo "Smrt a její reprezentace ve výtvarném umění středověku a novověku") [La muerte y su representación en las artes plásticas de la Edad Media y Moderna] en el suelo del Departamento de Sociología y Antropología de la Universidad de Ostrava. En agosto dio una conferencia con el título "Mexičtí Indiáni v proměnách času" [Los indígenas mexicanos en los cambios de tiempo] dentro del evento "Letní škola s FF UK" [Escuela de verano con FF UK] cuyo fin es presentar las carreras académicas de la Facultad de Filosofía y Letras de la Universidad Carolina a los estudiantes de escuelas secundarias. La misma participó en el curso de "Témata z dějin Latinské Ameriky ve 20. a 21. století" [Temas de la historia de América Latina de los siglos XX y XXI] que tuvo lugar en la Facultad de Filosofía y Letras de la Universidad Carolina con una charla sobre el arte latinoamericano de la segunda mitad del siglo XX en el contexto de los regímenes políticos.

En 2018 el Centro estableció la cooperación con una sección dedicada a la ciencia en la Televisión Checa. J. Opatrný comentó frecuentemente las relaciones internacionales entre América y el Occidente, participó por ejemplo en una discusión sobre Tony Cermak y Chicago junto con otros historiadores checos dentro de la emisión Historie.cs el 13 de octubre.

M. Brenišínová participó varias veces en las emisiones de la Televisión Checa, hablando, en julio: sobre las figuras en Perú, con una antigüedad mayor a dos mil años (la emisión Věda 24); en agosto: el descubrimiento de la máscara del gobernante maya en México (la emisión Studio ČT 24 ); en octubre: los nuevos descubrimientos en el Templo Mayor (la emisión Studio 6), en noviembre: el aniversario de la conquista de Cusco, la capital inca (la emisión Studio ČT 24 ) y conmemoración de los difuntos en la República Checa y en el mundo (la emisión Studio 6).

M. Brenišínová también apareció en noviembre en las ondas de la Radio Checa (Český rozhlas Vltava, la emisión Artcafé), hablando sobre la muerte en diferentes culturas, junto con el egiptólogo Martin Pehal y el eslavista Jiří Dynda.

Todos los colaboradores del Centro suelen ser autores de reseñas de libros con temas históricos para revistas tanto internacionales, como checas, especializadas o de divulgación.

\section{por Simona Binková, Monika Brenišínová y Anna Libánská (Praga) (Escrito en español por las autoras)}

https://doi.org/10.14712/24647063.2020.16 